\title{
Digitalization and Automation in University Libraries
}

\author{
Dr. Anita Malik \\ Chief Librarian, FIMT COLLEGE
}

\begin{abstract}
The purpose of this paper is to examine the present status of automation and digitization projects in university libraries and the challenges they pose to effective information delivery. It discusses the various aspects of the conversion of in-house library materials into electronic format, which leads toward the creation of digital library. The paper makes a more conscious effort on library automationation and implementation of digitization policies.
\end{abstract}

\section{INTRODUCTION}

In modern times, the library is constantly required to meet the challenges of information explosion. Assimilating resources and restructuring practices to process the large data volumes both in the print and digital form held across the globe, therefore, becomes very important. A recourse by the libraries to application of successive forms of what can be called as Digital Library Technologies (DLT) has been the imperative.

India has been the cradle of knowledge for thousands of years. Today there is a felt need to preserve and propagate indigenous knowledge and culture alongside the acceptance of universal knowledge through globalization in this age of technological developments. The IT oriented environment has brought in opportunities of a revolutionary nature in archiving and accessing knowledge in the digitized form which were known to exist in conventional libraries mainly in the print form. India has undertaken many initiatives to digitize its documented knowledge base and set up digital libraries for better access to its diverse clientele.

\section{ROLE OF LIBRARY}

Knowledge Management leveraging on information science (IS) and information technology (IT) is the recent trend and strategy seen in the advanced academic and corporate environment. Libraries, especially academic and research libraries, are perceived to be knowledge repositories of scholarly content. Scholarly communication is a complex mechanism acted up on by many stakeholders. Scholarly communication refers to the formal and informal processes by which the research and scholarship of researchers, faculty and independent scholars (freelance researchers) are created, evaluated, edited, formatted, distributed, organized, made accessible, archived, used, and transformed. Publishing is the formal system whose key players include researchers, publishers (including scholarly societies), and libraries (1). Over the past two decades dramatic changes have fundamentally reshaped the entire system of scholarly communication eco system. Recent advancements in technology and the advent of computers, Internet and communication technologies have revolutionised the scholarly communication scenario drastically. The first and foremost among these changes is the phenomenal increase in the body of published knowledge.

\section{Need of Library Automation}

Library automation which started in late 70 s in few special libraries has now reached most of the university libraries.

The factors necessitating automation of university libraries are the following:

$\Rightarrow$ Explosion of knowledge resulting in numerous specializations and flow of almost non-stop information;

$\Rightarrow$ Inability of users to explore unlimited literature; wastage of enormous precious time in handling routine and repetitive library operations; even the largest of the libraries cannot acquire and make available the entire published materials; and to facilitate easy, fast, and reliable sharing of resources between libraries, cutting across space and time.

\section{PRESENT STATUS}

In the information age, success lies in the innovative application of information technology and gaining access to digital resources. The university libraries in India have adopted state-of-the-art information technology for making the library and information services faster and effective. The automation of university libraries has gone a long way in providing quality service and facilitating easy access to varied information sources cutting across space and time. Adoption of IT has not only saved the time of scholars, it also widened 
the access base of information sources. In this context, the valuable support given by University Grants Commission (UGC) and Information and Library Network (INFLIBNET) Center is quite noteworthy.

\section{Expectation of Library Automation}

Computerisation of all the library house-keeping operations is known as library automation. Most commonly known housekeeping operations are acquisition, serials management, cataloguing and circulation. Depending on the type of library, all or some of these functions may be computerised according to their priority. Circulation control may be given first priority in a public library while serials control may be given a top priority in a special library. Similarly, acquisition may be computerised first in a university library. However, cataloguing is important for any library and its computerisation must be one of the ultimate aims of the automation programme.

\section{Electronic Database}

Due to emergence of Web technology, individuals, organizations and institutions are publishing their scholarly papers and publications on the Internet and the publishers are also changing their publication mode from print version to online electronic version. Vast resources are available on Internet which we can access in our library and information centers and provide the information to our users. Some of the important resources available on the Internet include Electronic Books, Electronic journals, Dictionaries, Directories, Reports, Patents, Standards, Library Catalogue, Newspapers, Magazines, Databases, Homepage of companies, Institutions, Organizations, Associations, individuals etc.

\section{Problems of Libraries and Information Centers to Access}

Though the Internet provides an open global networked environment for seamless publishing and access to information, yet, it is very difficult for small and medium sized libraries in India to procure and access these online sources, like, online e-journals, e-books, e-databases etc. due to their financial crunch. Moreover, some of the university libraries in India are not having sufficient fund to subscribe the core journals which are urgently necessary for research activities. In this situation the Library and Information professionals should take their own initiative to exploit the Internet for free available online resources. The place for exploitation of Internet by the Library and Information Centers are unlimited and endless. Internet provides a wealth of information to Library and Information Centers. It also provides free access to variety of information sources such as online e-books, e- Journals both full text, abstracts and contents depending on the publisher's policy, enews letters and so on.

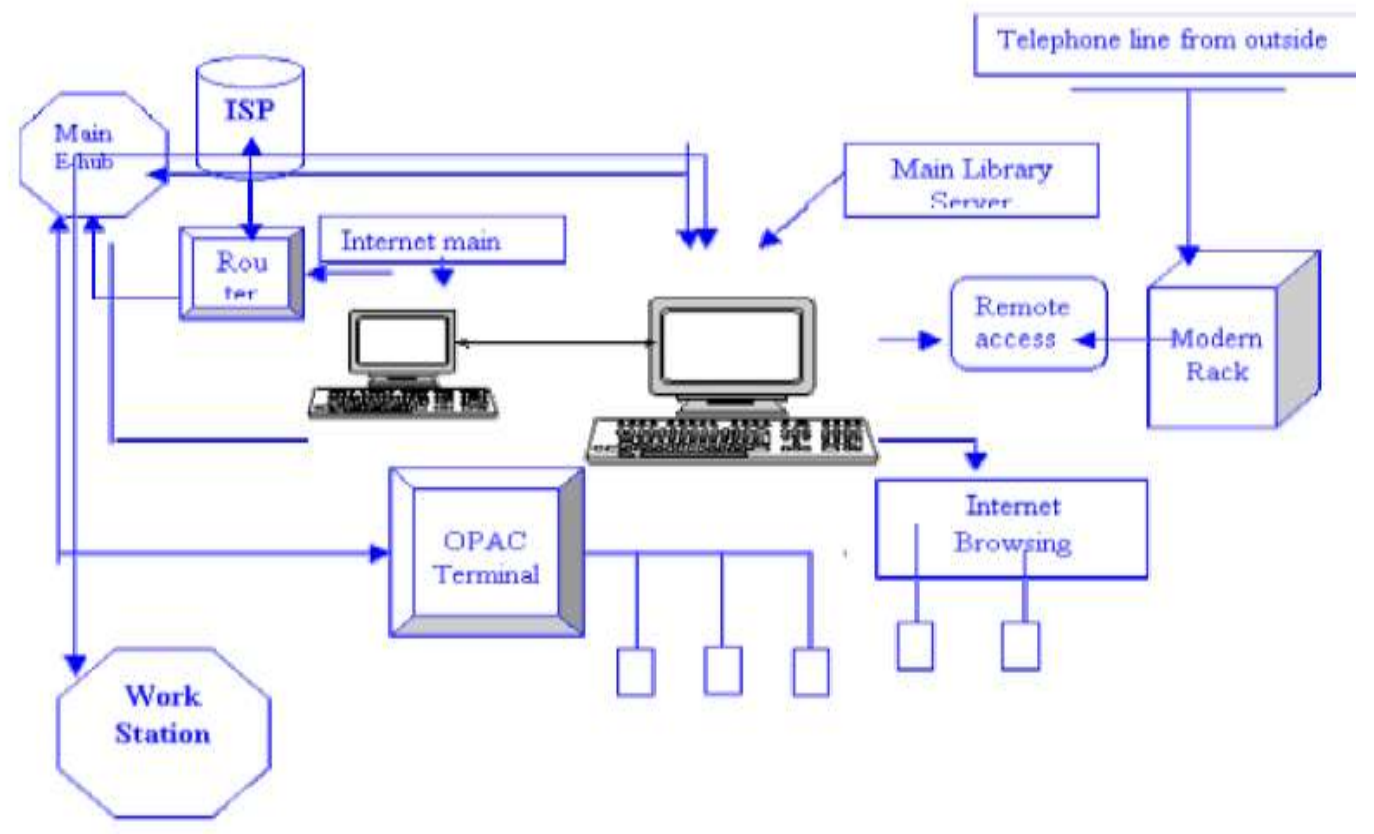

\section{Major Library Software's available} two as below:

There are several softwares available for library operations. In general, they may be categorized into 
Table showing different aspects of major library software's available in India

\begin{tabular}{|l|l|l|l|}
\hline LIBRARY SOFTWARE & APPLICATION & DEVELOPER & SUITABILITY \\
\hline CDS/ISIS & MS DOS, WINDOW 95, LAN, UNIX & NISSAT,NEW DELHI & $\begin{array}{l}\text { SMALL AND MEDIUM } \\
\text { LIBRARIES }\end{array}$ \\
\hline LIBSYS & MS DOS, WINDOW 95, LAN, UNIX & LIBSYS CO.,MEW DELHI & ALL TYPE OF LIBRARIES \\
\hline LIBRIS & MS DOS,WINDOW 95, LAN, UNIX & $\begin{array}{l}\text { FRONITER INST. OF INFO. } \\
\text { TECH.,HYDERABAD }\end{array}$ & ALL TYPE OF LIBRARIES \\
\hline SANJAY & MS DOS & NISSAT,NEW DELHI & $\begin{array}{l}\text { MEDIUM } \\
\text { LIBRARY }\end{array}$ \\
\hline ILMS & MS DOS,UNIX & INFLIBNET,AHMEDABAD & ALL TYPE OF LIBRARIES \\
\hline ALICE FOR WINDOW & WINDOW 95, LAN & $\begin{array}{l}\text { SOFTLINK INDIA,NEW } \\
\text { DELHI }\end{array}$ & ALL TYPE OF LIBRARIES \\
\hline BASIC PLUS & UNIX & NIC,NEW DELHI & ALL TYPE OF LIBRARIES \\
\hline
\end{tabular}

\section{Library Automation Activities in India}

The digital library is the most important development of 21 st century. It has opened up an exciting new world of information delivery for the researchers and citizens of tomorrow.

Digital technology can make the works of man or needed information accessible to all whether they live in a village or in an urban area. The father of Indian librarianship, Dr S. R. Ranganathan, in the past centuries has recognized the great potential of public libraries to improve the quality of life and provide opportunity the citizenry. Similarly digital libraries, widely available and accessible will improve the global society in ways beyond measurement. Hence, there is an urgent need of a workable strong strategy at the national level. The principal benefit of this will be to supplement the formal education system by making knowledge available to anyone who can have access. Several efforts are now being made in different parts of the country towards starting digitizing the existing resources and networking the existing institutions and libraries, especially suitable for accessibility mechanism. The major initiatives are briefly described below:

Government of India has set up NICNET which is the largest government owned information network. NIC is providing network backbone and e-governance to Central Government, State Government, UT Administrations, Districts and other Government bodies. It offers a wide range of ICT services including Nationwide Communication Network for decentralized planning, improvement in Government services and wider transparency of national and local Governments.

Similarly, Digital Library of India (DLI)-Universal library project is a major initiative. It is a collaborative project between Indian Institute of Science, Bangalore and Carnegie Mellor University with partners from the Government, Academia and Religious Institutions. The main objective of the project is to digitize all the significant literary, artistic, and scientific works of mankind and making them freely available, in every corner of the world, for our education, study and appreciation and for all our future generations.

Although some institutions like IS1 and IITs in the country have imported mainframe computers in the late1 950s and early 1960s, priority was being accorded for productivity-and R\&D-linked jobs.

Therefore, if one analyses these activities many unaddressed issues may be raised such as:

The objectives of the projects;

$\Rightarrow$ The rationale for content selection;

$\Rightarrow$ Preservation methods;

$\Rightarrow$ Access mechanism;

$\Rightarrow$ Coordination with other similar organizational initiatives;

$\Rightarrow$ Cost factor and sustainability etc.

Just as library automation was done in a very fragmented manner in India thirty years ago, the digitization activities are equally fragmented and diversified. This is in sharp contrast to some countries which have undertaken digitization and setting up of digital libraries in a planned manner with policies, strategies and structures well thought out, keeping in mind the holistic view of national need.

\section{Academic Libraries in India}

Academic libraries are considered to be the nerve centers of academic institutions, and must support teaching, research, and other academic programmes. The situation in academic libraries of India is the same as that of academic libraries the world over; however, Indian libraries must provide maximum information with limited resources.

\section{University Grants Commission (UGC)}

UGC, established by an act of parliament in 1956, coordinates and monitors the higher education system in India and provides grants to the universities and colleges. Two hundred ninety four universities/institutions in the country are directly under the purview of UGC. It also advises the union and state 
governments on measures to university education. It frames rules and regulations for overall teaching and research at higher education. As a result, it also looks after the academic libraries, i.e., sets various standards for library education, library staff, library services, etc. A number of committees have been set up by the UGC for the support of higher education in general and the library services in academic libraries in particular. UGC has also set up three information centers covering different disciplines - the National Centre for Science Information (NCSI) at Indian Institute of Science Bangalore, SNDT Women's University Mumbai and National Social Science Information Centre at M.S. University at Baroda, to provide the document delivery services to students, teachers, and researchers.

\section{Information and Library Network (INFLIBNET)}

The University Grants Commission has set up an autonomous Inter-University Centre in 1991 called INFLIBNET. It is involved in modernizing university libraries in India and connects them through a nationwide high-speed data network. It promotes automation of libraries, develops standards, creates union catalogues of serials, theses, books, monographs and non-book materials; provides access to bibliographic information sources; creates database of projects, institutions, specialists; provides training, etc. Almost all academic libraries, especially university libraries, are members of INFLIBNET. It has also developed library automation software called SOUL (Software for University Libraries) and has distributed the same free of cost to its member libraries.

\section{Other Networks}

Besides INFLIBNET, a number of other national networks and various library networks have also been developed including NICNET (National Informatic Center's network), INDONET, ERNET (Education and Research Network), CALIBNET (Calcutta Library Network), DELNET (Developing Library Network), etc. ADINET is associated with INFLIBNET, DELNET with NIC and MALIBNET with CFTRI. A number of educational institutions are members of such networks. These networks, especially DELNET (which has 752 member libraries including 742 from India and 10 from outside), are engaged in compiling union catalogs, creating various databases of experts, providing training to library staff, ILL, online facilities, reference service, assistance in retrospective conversion, etc.

\section{Library Consortia}

Due to a financial crunch and the rising costs of journals, many Indian university and college libraries cannot subscribe to all the required journals and databases. To overcome this problem, libraries are forming consortia. Some special libraries and organizations like the Indian Institute of Astrophysics (IIA) Library, Interuniversity Centre for Astronomy and Astrophysics (IUCAA) Library, National Centre for Radio Astrophysics (NCRA) Library, Physical Research Laboratory (PRL) Library, Raman Research Institute (RRI) Library, Tata Institute of Fundamental Research (TIFR) Library, Council of Scientific and Industrial Research, Department of Atomic Energy, etc., have established consortia to share electronic access to journal literature. NISCAIR (formed by the merger of INSDOC and NISCOM) is developing a consortium for CSIR labs for accessing ejournals.

The e-subscription initiative under UGC-Infonet is an important portal for sharing print as well as electronic resources amongst university libraries. INFLIBNET functions as a resource center with an aim to cater to the needs of its members for resources not accessible to them in electronic media or are available in print media.

\section{Objectives of the Study}

1. To study about electronic publishing

2. To study and elaborate the need for digitalization and automation in Libraries

3. To analyze the impact of digitalization and automation in the selected libraries in Universities.

\section{Research Methodology}

A Research Methodology defines the purpose of the research, how it proceeds, how to measure progress and what constitute success with respect to the objectives determined for carrying out the research study. The appropriate research design formulated is detailed below.

Exploratory research: this kind of research has the primary objective of development of insights into the problem. It studies the main area where the problem lies and also tries to evaluate some appropriate courses of action. The research methodology for the present study has been adopted to reflect these realties and help reach the logical conclusion in an objective and scientific manner. The present study contemplated an exploratory research 
Table shows reference services

\begin{tabular}{|l|l|l|}
\hline Kind of Reference & No. of Users & $\%$ \\
\hline Encyclopedia & 34 & $34 \%$ \\
\hline Dictionaries & 24 & $24 \%$ \\
\hline Directories & 26 & $24 \%$ \\
\hline Biographies & - & - \\
\hline Yearbook & 34 & $34 \%$ \\
\hline Bibliographies & 24 & $24 \%$ \\
\hline Handbook & 8 & $8 \%$ \\
\hline Union Catalogue & 10 & $16 \%$ \\
\hline Union List & - & - \\
\hline Index & - & - \\
\hline Abstract & - & - \\
\hline Statistical Sources & - & - \\
\hline
\end{tabular}

Analysis of Data Collection

The above table shows that in university libraries $100 \%$ users use circulation service, $72 \%$ users use reference service and $60 \%$ of users use ILL service and $30 \%$ users use Book Bank Facilities Service in college library

\section{Conclusion}

In this current information technology age, use of computers for library house-keeping operations is not simply feasible, but inevitable. It has become a necessity than anything else. Many networks are now emerging in India. For participation and also the effective utilisation of network resources, it is necessary for the participating members to automate their libraries. Although required hardware for library automation is now available at a reasonable cost; software packages are however not easily available. Before introducing automation a comprehensive evaluation of the library requirements, software features needed, and capabilities of the hardware for implementing the software has to be made.

Digital technology has raised the hopes and expectations of people to face the challenges of not only bridging the gap between the information rich and the information poor in the country, but also uplifting the level of development in all its different facets. Major responsibility now rests on the decision makers, technological experts, librarians, educationists, social workers, experts, publishing industry as well as the local institutions to play their respective roles in bringing digital information in need based comprehensible form and language to the diverse clientele of the country. No agency can really work in isolation to reach the expected goal in the right manner.

\section{References}

[1] Misra, V. N. and Phadke, D. N. "Information Technology and Libraries" In Computer Application in Library and Information Science, edited by D. C. Ojha. Jodhpur: Scientific Publisher, 1995

[2] Francis, A.T. Regional Information Networks: necessary thrust area for INFLIBNET to establish integrated information system in India. In "Information Technology applications in Academic Libraries" edited by A.L. Murthy and P.B.Mangala P. 102106.Ahmedabad: INFLIBNET, 1997

[3] International Development Research Centre. MINISIS: information management solutions. Ottawa, Canada: IDRC.(Leaflet)

[4] National Academy of Agricultural Research Management. Proceedings of the workshop on Software Review for Library Automation, Hyderabad, July 28-30, 1997.

[5] Rowley, J.E. Guidelines on the evaluation and selection of library software packages. ASLIB Proceedings 42(9) P. 225-235.

[6] Sreedevi Ravindran. Status Report on the use of Micro-ISIS in India: 1997. Paper presented at the 7th CDS/ISIS Users' Group Meet, Bhubaneswar, 26-28, Nov. 1997.

[7] Kaul, H.K. Library resource sharing and networks. Virgo Publication, New Delhi , 1999.

[8] Murthy, T.A.V. Resource sharing and consortia for India. Proceeding of the Seminar held at IIT , Kharagpur, Feb. 2002. Pp.14-15.

[9] Rama Verma and Janak Raj, "Practical aspects of library automation in the Indian context," In Information Technology Application in Academic Libraries, edited by A.L. Moorthy and P.B. Mangla (Ahmedabad:INFLIBNET Centre, 1997) pp. 10-14.

[10] a special reference to Indian University Libraries," The International Information \& Library Review, 35(2003): 375-382.

[11] Manoj Kumar Sinha, "Scenario of automation and networking of library and information centers of north eastern region of India: an evaluative study," In Information Technology Application in Academic Libraries, edited by A.L. Moorthy and P.B. Mangla (Ahmedabad:INFLIBNET Centre, 1997) pp. 1-4.

[12] Anil Singh, "Library automation and networking software in India," Information Development, 19(2003): 51-55. 